\title{
DETERMINAÇÃO DAS FORMAS DE NITROGÊNIO E NITROGÊNIO TOTAL EM ROCHAS-RESERVATÓRIO DE PETRÓLEO POR DESTILAÇÃo COM ARRASTE DE VAPOR E MÉTODO DO INDOFENOL
}

\author{
Lílian Irene Dias da Silva, Manuel Castro Carneiro, Vanessa dos Santos Emídio, Sérgio de Souza Henrique Junior e \\ Maria Inês Couto Monteiro* \\ Centro de Tecnologia Mineral, Coordenação de Análises Minerais, Av. Ipê, 900, Ilha da Cidade Universitária,
}

21941-590 Rio de Janeiro-RJ

Recebido em 28/10/04; aceito em 20/5/05; publicado na web em 25/11/05

\begin{abstract}
DETERMINATION OF NITROGEN FORMS AND TOTAL NITROGEN IN PETROLEUM RESERVOIR ROCKS BY STEAM DISTILLATION AND THE INDOPHENOL METHOD. Several extraction procedures are described for the determination of exchangeable and fixed ammonium, nitrate + nitrite, total exchangeable nitrogen and total nitrogen in certified reference soils and petroleum reservoir rock samples by steam distillation and indophenol method. After improvement of the original distillation system, an increase in worker safety, a reduction in time consumption, a decrease of $73 \%$ in blank value and an analysis without ammonia loss, which could possibly occur, were achieved. The precision (RSD $\leq 8 \%, \mathrm{n}=3)$ and the detection limit $\left(9 \mathrm{mg} \mathrm{kg}^{-1} \mathrm{NH}_{4}^{+}-\mathrm{N}\right)$ are better than those of published procedures.
\end{abstract}

Keywords: nitrogen; rock; soil.

\section{INTRODUÇÃO}

Nitrogênio geológico, termo que se refere ao nitrogênio incorporado na matriz da rocha durante a diagênese ou através de alteração secundária ${ }^{1}$, é um dos componentes das rochas-reservatório de petróleo que participam de reações microbianas ${ }^{2}$. A determinação das formas desse nitrogênio é extremamente importante para subsidiar projetos na área de ecologia de reservatórios petrolíferos. Entretanto, na literatura não há métodos para determinação das formas de nitrogênio em tais matrizes.

$\mathrm{O}$ nitrogênio apresenta-se nas rochas, solos e sedimentos em diferentes formas, quais sejam: $\mathrm{NH}_{3}, \mathrm{NH}_{4}^{+}, \mathrm{NO}_{\mathrm{x}}$ ou $\mathrm{N}$ ligado quimicamente a moléculas orgânicas ou inorgânicas ${ }^{3}$. Os íons $\mathrm{NH}_{4}^{+}$ nos solos e sedimentos podem estar fracamente adsorvidos na superfície $\left(\mathrm{NH}_{4}^{+}\right.$troćvel $)$ou fixos nos espaços interlamelares dos minerais argilosos $\left(\mathrm{NH}_{4}^{+}\right.$fixo $)$. As formas envolvidas nos equilíbrios dependem da concentração de $\mathrm{N}_{\text {total }}$, atividade bacteriana, condições redox e qualidade da fase aquosa associada. A quantidade de amônio fixo depende da disponibilidade do íon $\mathrm{NH}_{4}^{+}$durante a formação dos minerais argilosos e da capacidade de fixação desses minerais ${ }^{4}$. Nas rochas, a maior parte do nitrogênio está provavelmente presente como íon amônio 5 .

Os métodos mais utilizados para a determinação de $\mathrm{N}_{\text {total }}$ são método Kjeldahl (método TKN), que é essencialmente um procedimento de oxidação úmida ${ }^{6}$ e método de Dumas, que é basicamente uma técnica de oxidação seca (combustão) ${ }^{7}$. De acordo com Wang et al. ${ }^{8}$, ambas as técnicas são adequadas e comparáveis quando a concentração de nitrogênio é de aproximadamente $200 \mathrm{mg} \mathrm{kg}^{-1}$. Para concentrações menores, o método mais adequado é o TKN que, entretanto, em concentrações menores que $25 \mathrm{mg} \mathrm{kg}^{-1} \mathrm{~N}$, apresenta altos coeficientes de variação.

Bremner $^{6}$ apresenta uma ampla discussão sobre o método TKN aplicado aos solos, utilizado para determinação de nitrogênio total $\left(\mathrm{N}_{\text {total }}\right)$ desde $1883^{\circ}$. O método apresenta como principais vantagens o uso de uma aparelhagem extremamente simples e pouco

*e-mail: mmonteiro@cetem.gov.br onerosa, e é satisfatório para a análise de $\mathrm{N}_{\text {total }}$ para a maioria dos compostos nitrogenados que ocorre nos solos e plantas $\left(\mathrm{N}_{\text {orgânico }} \mathrm{e}\right.$

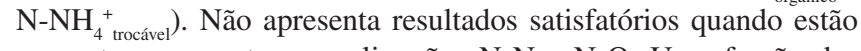
presentes compostos com ligações $\mathrm{N}-\mathrm{N}$ e N-O. Uma fração das

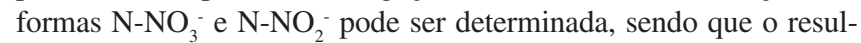
tado é muito variável, dependendo da quantidade de água e de matéria orgânica presente no solo. Altas recuperações podem ser obtidas com solos orgânicos ${ }^{6}$. As formas ${\mathrm{N}-\mathrm{NH}_{4}^{+} \text {fixo }}^{7} \mathrm{e} \mathrm{N}_{\text {orgânico }}{ }^{6}$ retidas nas camadas interlamelares das amostras superficiais de minerais argilosos e de solos orgânicos são determinadas quantitativamente pelo método TKN, porém para subsolos contendo altas concentrações de $\mathrm{N}_{-} \mathrm{NH}_{4}^{+}$fixo este método não fornece resultados exatos de $\mathrm{N}$ $\mathrm{NH}_{4}^{+}$fixo nativo.

O método clássico TKN compreende duas etapas: digestão da amostra para converter $\mathrm{N}_{\text {orgânico }}$ a íon amônio $\left(\mathrm{N}^{\left.-\mathrm{NH}_{4}^{+}\right)}\right.$e determinação do $\mathrm{N}_{-} \mathrm{NH}_{4}^{+}$, obtido em meio ácido, após destilação da amônia com arraste de vapor. $\mathrm{O}$ íon $\mathrm{NH}_{4}^{+}$é então, determinado por espectrofotometria, eletrodo íon seletivo ou titulação com solução padrão ácida. $\mathrm{O}$ método titrimétrico é comumente utilizado para análise de $\operatorname{solos}^{6,10}$, e consiste na determinação do $\mathrm{H}_{2} \mathrm{BO}_{3}^{-}$, através da titulação com solução-padrão de ácido mineral ${ }^{6,9,11,12}$. Entre os métodos espectrofotométricos mais sensíveis, o método do indofenol é utilizado principalmente para análise de águas ${ }^{13}$.

O método do indofenol baseia-se na formação do composto azul intenso de indofenol (reação de Berthelot), resultante da reação do íon amônio com um composto fenólico, na presença de um agente oxidante e de um catalisador ${ }^{12-19}$. É um método que apresenta valores altos e variáveis de branco ${ }^{8,20}$, e na faixa de concentração micromolar, a precisão é raramente melhor que cerca de $10 \%{ }^{20}$.

A determinação dos íons inorgânicos trocáveis de nitrogênio $\mathrm{N}$-( $\mathrm{NH}_{4}^{+}$trocável, $\left.\mathrm{NO}_{3}^{-}, \mathrm{NO}_{2}^{-}\right)$em solos geralmente consiste de duas etapas: extração dos íons em fase aquosa e análise do extrato ${ }^{21,22}$. $\mathrm{Na}$ literatura, são apresentados diferentes extratores para as formas $\mathrm{N}-\left(\mathrm{NH}_{4}^{+}\right.$trocável $\left., \mathrm{NO}_{3}^{-}, \mathrm{NO}_{2}{ }^{-}\right)$presentes nos solos ${ }^{21,23}$, rochas ${ }^{11} \mathrm{e}$ sedimentos ${ }^{4,22,24}$. Entretanto, o íon mais favorável para a troca com o íon amônio é o íon potássio ${ }^{4}$ e, conseqüentemente, a solução extratora de $\mathrm{KCl}$ tem sido muito utilizada para extração de todas as 
formas de $\mathrm{N}-\left(\mathrm{NH}_{4}^{+} \text {trocável } \mathrm{NO}_{3}^{-}, \mathrm{NO}_{2}^{-}\right)^{4,21,23-25}$. O extrato tem sido analisado por técnicas colorimétricas ${ }^{24,26-28}$, destilação com arraste de vapor $^{11,21}$ ou eletrodo íon seletivo $0^{4,23,29,30}$.

Os métodos mais utilizados para a determinação de $\mathrm{N}_{-} \mathrm{NH}_{4}^{+}$fixo em folhelhos, rochas ${ }^{11,25,31}$, solos e $\operatorname{argilas}^{32}$ baseiam-se na extração com HF, após um pré-tratamento da amostra com KOH e aquecimento, e posterior determinação do íon $\mathrm{NH}_{4}^{+}$. Para evitar o ataque do vidro do tubo de destilação pelo extrato de $\mathrm{HF}$, foram propostos vários procedimentos: Dhariwal e Stevenson ${ }^{32}$, adicionaram previamente ao tubo de destilação a solução de $\mathrm{NaOH}$ e, em seguida, o extrato; Stevenson ${ }^{25}$ aqueceu o extrato até próximo à secura e Stevenson ${ }^{11}$ neutralizou o extrato com solução de $\mathrm{NaOH}$ várias horas antes da destilação.

Este trabalho tem como objetivo a implementação de métodos simples, precisos e exatos para determinação das formas de nitrogênio e de nitrogênio total em amostras de rocha-reservatório de petróleo.

\section{PARTE EXPERIMENTAL}

\section{Equipamentos}

Para determinação de nitrogênio total, foi utilizado um bloco digestor TE-008/25 com capacidade para 8 provas micro, fornecido pela Tecnal (Piracicaba - SP, Brasil). Foi construído um sistema em vidro Pyrex, para sucção por vácuo do $\mathrm{SO}_{3}$ produzido durante a digestão das amostras.

Para extração das formas trocáveis de nitrogênio, foi utilizada uma mesa agitadora orbital Marconi MA 141 na velocidade máxima, e para separação das fases sólida e líquida foi utilizada uma centrífuga CELM, modelo LS-3 plus, na velocidade de 3200 rpm, durante $30 \mathrm{~min}$.

Para destilação da amônia, foi utilizado um destilador modelo TE 036/1 também da Tecnal, semi-automático acoplado a um banho termostatizado Nova Ética, contendo água Milli-Q entre 16 e $20{ }^{\circ} \mathrm{C}$.

Para determinação de nitrogênio total, foi utilizado o tubo origi-

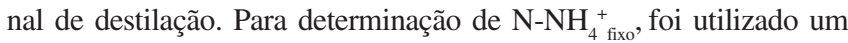
tubo de destilação modificado de polipropileno, para evitar ataque do vidro pelos extratos de HF. Para destilações seqüenciais de $\mathrm{N}$ $\mathrm{NH}_{4}^{+}$e N-( $\left.\mathrm{NO}_{3}^{-}+\mathrm{N}^{-} \mathrm{NO}_{2}^{-}\right)$, foi utilizado um tubo de destilação modificado de vidro com um volume maior $(300 \mathrm{~mL})$ que o original (100 mL) e com uma válvula especial, que mantém o sistema de destilação sempre fechado durante a adição da liga de Devarda.

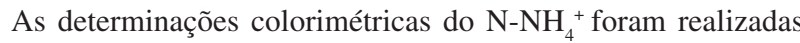
em espectrofotômetro Perkin-Elmer Lambda 12/1.0 nm (1.3) com detector UV-Vis, utilizando celas de $1 \mathrm{~cm}$ de caminho óptico.

A temperatura dos poços do bloco digestor foi monitorada utilizando um termopar CONTEMP, Indústria, Comércio e Serviços LTDA, modelo IM-01, entrada K(IPTS).

Os difratogramas de raios $\mathrm{X}$ das amostras, obtidos pelo método do pó, foram coletados em um equipamento Bruker-AXS D5005 equipado com espelho de Goeble para feixe paralelo de raios X,

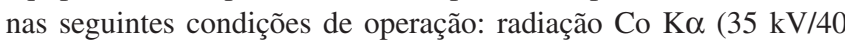
$\mathrm{mA}$ ); velocidade do goniômetro de $0,02^{\circ} 2 \theta$ por passo com tempo de contagem de $1,0 \mathrm{~s}$ por passo e coletados de 5 a $80^{\circ} 2 \theta$. A interpretação qualitativa foi efetuada por comparação com padrões contidos no banco de dados PDF02 (ICDD, 1996) em software Bruker Diffrac ${ }^{\text {Plus }}$.

\section{Reagentes, soluções e amostras}

Foram utilizados ácido sulfúrico, hidróxido de sódio e ácido fluorídrico fornecidos pela Vetec Química Fina Ltda; sulfato de cobre, sulfato de potássio, cloreto de amônio, fenol e nitroprussiato de sódio fornecidos pela Merck e hipoclorito de sódio da Isofar. Todas as soluções foram preparadas utilizando reagentes de grau analítico (P.A.) e água destilada e deionizada purificada em um sistema Milli-Q.

Na etapa de digestão das amostras para determinação de nitrogênio total, foi utilizada uma solução ácida digestora, constando de $10 \mathrm{~g}$ da mistura de sulfato de potássio + sulfato de cobre (na proporção de $3: 1 \mathrm{~m} / \mathrm{m}$ e triturados em um gral de ágata), $100 \mathrm{~mL}$ de água e $100 \mathrm{~mL}$ de $\mathrm{H}_{2} \mathrm{SO}_{4}$ concentrado. Para extração das formas trocáveis de nitrogênio, foi utilizada uma solução extratora de cloreto de potássio $0,4 \mathrm{~mol} \mathrm{~L}^{-1} \mathrm{em} \mathrm{pH} \mathrm{2,5}$ (ajustado com $\mathrm{HCl}$ ). $\mathrm{Na}$ etapa de destilação da amônia, foram utilizadas as soluções de hidróxido de sódio $10 \mathrm{~mol} \mathrm{~L}{ }^{-1}$ e de ácido sulfúrico $0,9 \mathrm{mmol} \mathrm{L}^{-1}$. Para determinação colorimétrica do íon $\mathrm{NH}_{4}^{+}$pelo método do indofenol, foram utilizadas as seguintes soluções: solução-padrão estoque de amônio $100 \mathrm{mg} \mathrm{L}^{-1} \mathrm{~N}_{-} \mathrm{NH}_{4}^{+}$, a partir do $\mathrm{NH}_{4} \mathrm{Cl}$ anidro; solução-padrão intermediária de amônio $10 \mathrm{mg} \mathrm{L}^{-1} \mathrm{~N}_{-} \mathrm{NH}_{4}^{+}$; soluções-padrão de amônio 0,05 a $0,5 \mathrm{mg} \mathrm{L}^{-1} \mathrm{~N}_{-} \mathrm{NH}_{4}^{+}$em $\mathrm{H}_{2} \mathrm{SO}_{4}$ $0,036 \mathrm{mM}$; solução-padrão estoque mista de $100 \mathrm{mg} \mathrm{L}^{-1} \mathrm{~N}_{-\mathrm{NO}_{3}^{-}+}+$ $100 \mathrm{mg} \mathrm{L}^{-1} \mathrm{~N}_{-} \mathrm{NO}_{2}^{-}$, a partir do nitrato de potássio e nitrito de sódio, respectivamente; solução-padrão intermediária mista de $10 \mathrm{mg} \mathrm{L}^{-1}$ $\mathrm{N}^{-\mathrm{NO}_{3}}{ }^{-}+10 \mathrm{mg} \mathrm{L}{ }^{-1} \mathrm{~N}_{-} \mathrm{NO}_{2}$; solução de fenol $(5 \% \mathrm{~m} / \mathrm{v})+$ nitroprussiato de sódio $(0,025 \% \mathrm{~m} / \mathrm{v})$; solução de hipoclorito de sódio (contendo aproximadamente $0,21 \%$ de cloro ativo) + hidróxido de sódio $(2,5 \% \mathrm{~m} / \mathrm{v})$.

Foram analisados três materiais de referência certificados de solo, NCS DC 73319, 73321, 73326, com valores certificados de nitrogênio total de $1870 \pm 54,640 \pm 40$ e $370 \pm 43 \mu \mathrm{g} \mathrm{g}^{-1}$, respectivamente, fornecidos pelo China National Analysis Center for Iron and Steel (Beijing - China), e duas amostras de rocha de reservatório petrolífero 7 e 9 . Amostras de referência de rocha-reservatório de petróleo não são disponíveis no mercado.

\section{Pré-tratamento das amostras de rocha-reservatório}

Uma massa de aproximadamente $300 \mathrm{~g}$ de cada amostra contendo óleo, foi transferida para béquer de $1000 \mathrm{~mL}$. Foram adicionados $500 \mathrm{~mL}$ de $\mathrm{n}$-hexano, o béquer foi tampado com vidro de relógio, e a mistura foi agitada manual e ocasionalmente por $2 \mathrm{~h}$. Em seguida, a mistura foi filtrada em papel de filtro de filtração rápida. Foram adicionadas porções individuais de $300 \mathrm{~mL}$ de nhexano até a completa remoção do óleo. Finalmente, a amostra foi seca ao ar por um período de $12 \mathrm{~h}$, homogeneizada e pulverizada em gral de porcelana, para passar em peneira de 150 mesh.

\section{Determinação de nitrogênio total}

A determinação de nitrogênio total foi baseada no procedimento descrito na literatura ${ }^{8,13}$. O bloco digestor foi previamente aquecido a $150{ }^{\circ} \mathrm{C}$. Cerca de $0,2 \mathrm{~g}$ de amostra foram transferidos para $\mathrm{o}$ tubo digestor e adicionados $5 \mathrm{~mL}$ da solução ácida digestora, contendo $\mathrm{K}_{2} \mathrm{SO}_{4}$ para aumentar a temperatura de ebulição do $\mathrm{H}_{2} \mathrm{SO}_{4}$ e do catalisador $\mathrm{CuSO}_{4}$. O tubo foi agitado manualmente para melhorar o contato da amostra com a solução e, então colocado no poço, sendo a temperatura mantida a $150{ }^{\circ} \mathrm{C}$ por $1 \mathrm{~h}$. Em seguida, o botão do termostato foi levado a $400{ }^{\circ} \mathrm{C}$ e, quando a temperatura foi atingida, foi mantida por $2 \mathrm{~h}$. Após o arrefecimento do tubo contendo o digerido à temperatura ambiente (cerca de 30-40 min), foram adicionados cuidadosamente $20 \mathrm{~mL}$ de água e o tubo foi conectado ao destilador Kjeldahl. Foi adicionado, cuidadosamente, um excesso $(10 \mathrm{~mL})$ de $\mathrm{NaOH} 10 \mathrm{~mol} \mathrm{~L}^{-1}$ através do funil de 
adição, para transformar $\mathrm{NH}_{4}^{+} \mathrm{em} \mathrm{NH}_{3}$, fechando-se imediatamente o sistema de destilação. Em seguida, foi ligado o aquecimento da caldeira de vapor, já previamente aquecida até a ebulição, e o destilado foi recolhido.

\section{Determinação das formas inorgânicas trocáveis de nitrogênio}

Os procedimentos para extração e determinação das formas inorgânicas trocáveis de nitrogênio foram adaptados da literatura ${ }^{21}$. Para implementação do método para determinação do $\mathrm{N}_{-} \mathrm{NH}_{4}^{+}$trocável nas amostras, foram estudados diversos parâmetros, quais sejam: tempo de extração, $(t=$ zero, $t=30 \min$ e $t=1 \mathrm{~h})$, utilizando a solução de $\mathrm{KCl} 0,2 \mathrm{~mol} \mathrm{~L}^{-1}$, concentração do extrator $(0,2$ e $0,4 \mathrm{~mol}$ $\left.\mathrm{L}^{-1}\right)$ e tipo de extrator $\left(\mathrm{KCl} \mathrm{0,4} \mathrm{mol} \mathrm{L}^{-1}\right.$ e $\left.\mathrm{NaCl} 0,4 \mathrm{~mol} \mathrm{~L}^{-1}\right)$, usando nos dois últimos estudos, o tempo de extração de $30 \mathrm{~min}$. O procedimento foi semelhante ao descrito no método otimizado.

\section{Método otimizado para extração das formas inorgânicas trocáveis de nitrogênio}

Cerca de $5 \mathrm{~g}$ de amostra foram transferidos para um frasco de polipropileno de $250 \mathrm{~mL}$. Foram adicionados $140 \mathrm{~mL}$ de extrator $\mathrm{KCl} 0,4 \mathrm{~mol} \mathrm{~L}^{-1}$, e a mistura foi agitada mecanicamente por 30 min, mantendo-se o frasco fechado e em posição vertical. Ao término da agitação, a mistura foi mantida em repouso por $30 \mathrm{~min}$ e, em seguida, as fases foram separadas através de centrifugação por $30 \mathrm{~min}$. Foram retiradas três alíquotas de $20 \mathrm{~mL}$ do sobrenadante com uma pipeta, para determinação do nitrogênio trocável total $\left(\mathrm{N}_{\text {trocável total }}\right)$, amônio trocável $\left(\mathrm{N}_{-} \mathrm{NH}_{4}^{+}{ }_{\text {trocável }}\right)$ e nitrato + nitrito $\mathrm{N}$ $\left(\mathrm{NO}_{3}^{-}+\mathrm{NO}_{2}^{-}\right)$.

\section{Determinação de nitrogênio trocável total}

Para determinação de $\mathrm{N}_{\text {trocável total }}$, foram adicionados $0,2 \mathrm{~g}$ de $\mathrm{MgO}$ e $0,2 \mathrm{~g}$ de liga de Devarda ao tubo de destilação original. A adição de $\mathrm{MgO}$ teve como finalidade garantir um meio básico sem promover a liberação do nitrogênio orgânico, enquanto que a liga de Devarda foi utilizada para redução de nitrato e nitrito ao íon amônio. Uma alíquota de $20 \mathrm{~mL}$ do extrato foi submetida à destilação.

\section{Determinação das formas inorgânicas trocáveis de nitrogênio}

Para determinação de $\mathrm{N}-\mathrm{NH}_{4}^{+}$trocável $\mathrm{e} \mathrm{N}-\left(\mathrm{NO}_{3}^{-}+\mathrm{NO}_{2}^{-}\right)$, foram realizadas duas destilações seqüienciais. Primeiramente, foram adicionados $0,2 \mathrm{~g}$ de $\mathrm{MgO}$ ao tubo de destilação modificado de vidro, e uma alíquota de $20 \mathrm{~mL}$ do extrato foi submetida à destilação para determinação de $\mathrm{N}^{-} \mathrm{NH}_{4}^{+}$trocável . Em seguida, a solução restante no tubo de destilação modificado foi submetida à destilação, após a adição de 0,2 g de liga de Devarda, através da válvula especial, para determinação de $\mathrm{N}-\left(\mathrm{NO}_{3}^{-}+\mathrm{NO}_{2}^{-}\right)$.

\section{Determinação de amônio fixo}

A determinação de $\mathrm{N}^{-} \mathrm{NH}_{4}^{+}$fixo foi baseada no procedimento descrito por Dhariwal e Stevenson ${ }^{32}$. Cerca de $0,2 \mathrm{~g}$ de amostra foram transferidos para um tubo de centrífuga de polipropileno de $50 \mathrm{~mL}$, seguido da adição de $25 \mathrm{~mL}$ de $\mathrm{KOH} 1 \mathrm{~mol} \mathrm{~L}^{-1}$ e aquecimento em banho-maria a $80^{\circ} \mathrm{C}$ por $8 \mathrm{~h}$. O tratamento com $\mathrm{KOH}$ teve como finalidade evitar interferências resultantes da desaminação de materiais orgânicos nitrogenados. Após arrefecimento à temperatura ambiente, a mistura foi centrifugada, o sobrenadante (contendo $\mathrm{N}_{-} \mathrm{NH}_{4}^{+}$trocável $+\mathrm{N}_{\text {org. }}$ ) descartado, e o resíduo lavado três vezes com porções de $5 \mathrm{~mL}$ de $\mathrm{KOH} 1 \mathrm{~mol} \mathrm{~L}^{-1}$ e finalmente com $5 \mathrm{~mL}$ de água. Ao resíduo foram adicionados $10 \mathrm{~mL}$ de uma mistura contendo $\mathrm{HF} 7,5 \mathrm{~mol} \mathrm{~L}^{-1}$ e $\mathrm{HCl} 1,0 \mathrm{~mol} \mathrm{~L}^{-1}$. A mistura foi aquecida em banho de areia a $80^{\circ} \mathrm{C}$ por 12 a $16 \mathrm{~h}$, até próximo à secura.
Após arrefecimento à temperatura ambiente, a mistura foi transferida para o tubo de destilação modificado de polipropileno, com ajuda de $\mathrm{HCl} 0,1 \mathrm{~mol} \mathrm{~L}^{-1}$, e submetida à destilação, após a adição de um excesso $(10 \mathrm{~mL})$ de $\mathrm{NaOH} 10 \mathrm{~mol} \mathrm{~L}^{-1}$.

\section{Recolhimento do destilado para determinação das formas de nitrogênio e de nitrogênio total}

O destilado foi recolhido em um frasco erlenmeyer de $125 \mathrm{~mL}$, contendo $20 \mathrm{~mL}$ de $\mathrm{H}_{2} \mathrm{SO}_{4} 0,9 \mathrm{mmol} \mathrm{L}^{-1}$, até o volume próximo de $50 \mathrm{~mL}$ (o tempo total de destilação foi aproximadamente de $3 \mathrm{~min}$ ) e reservado para determinação espectrofotométrica do íon $\mathrm{NH}_{4}^{+}$.

\section{Determinação espectrofotométrica do íon amônio pelo método do indofenol}

O método do indofenol foi baseado no procedimento descrito na literatura ${ }^{13}$. O destilado foi transferido para um balão volumétrico de $50 \mathrm{~mL}$ e avolumado com água. Uma alíquota de $2,5 \mathrm{~mL}$ do

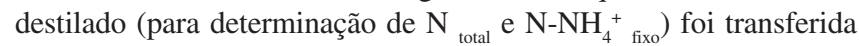
para um balão volumétrico de $25 \mathrm{~mL}$; no caso das formas trocáveis, foi pipetada uma alíquota de $20 \mathrm{~mL}$ do destilado. Foram adicionados $2 \mathrm{~mL}$ de nitroprussiato de sódio + fenol e, após homogeneização, foram adicionados $2 \mathrm{~mL}$ da solução de hipoclorito de sódio + hidróxido de sódio. O volume foi completado com água e a mistura novamente homogeneizada. A mistura foi mantida em repouso por $30 \mathrm{~min}$ para desenvolvimento da cor.

\section{Estudo da estabilidade do nitroprussiato-fenol e do indofenol}

A estabilidade do reagente nitroprussiato-fenol foi estudada através da preparação diária do composto indofenol em soluçõespadrão de $\mathrm{NH}_{4} \mathrm{Cl}$ em $\mathrm{H}_{2} \mathrm{SO}_{4} 0,036 \mathrm{mmol} \mathrm{L}^{-1}$, contendo $0,1,0,3 \mathrm{e}$ $0,5 \mathrm{mg} \mathrm{L}^{-1} \mathrm{~N}_{-\mathrm{NH}_{4}^{+}}^{+}$, diluindo-se adequadamente a solução-padrão intermediária de $10 \mathrm{mg} \mathrm{L}^{-1} \mathrm{~N}-\mathrm{NH}_{4}^{+}$, recém preparada. $\mathrm{O}$ reagente nitroprussiato-fenol foi estocado em um balão volumétrico, recoberto com papel de alumínio, para evitar a incidência da luz, e mantido em refrigerador $\left(4{ }^{\circ} \mathrm{C}\right)$. $\mathrm{O}$ reagente foi utilizado após atingir a temperatura ambiente.

$\mathrm{O}$ estudo da estabilidade do composto indofenol foi realizado com soluções-padrão de $\mathrm{NH}_{4} \mathrm{Cl}$ em $\mathrm{H}_{2} \mathrm{SO}_{4} 0,036 \mathrm{mmol} \mathrm{L}^{-1}$, contendo $0,1,0,3$ e $0,5 \mathrm{mg} \mathrm{L}^{-1}$ de $\mathrm{N}_{-} \mathrm{NH}_{4}^{+}$, diluindo-se adequadamente a solução-padrão estoque de $100 \mathrm{mg} \mathrm{L}^{-1} \mathrm{de} \mathrm{N}^{-\mathrm{NH}_{4}+}$. As soluções coloridas foram mantidas em balões volumétricos de vidro transparente e à temperatura de cerca de $4{ }^{\circ} \mathrm{C}$, em refrigerador. As medidas da absorvância das soluções foram realizadas após as soluções atingirem a temperatura ambiente.

\section{Construção das curvas de calibração}

Foram construídas curvas analíticas com concentrações finais de 0,05 a $0,5 \mathrm{mg} \mathrm{L}^{-1}$ de $\mathrm{N}$, pipetando-se inicialmente alíquotas de 0,25 a $2,5 \mathrm{~mL}$ da solução-padrão de $100 \mathrm{mg} \mathrm{L}^{-1}$ de $\mathrm{N}_{-} \mathrm{NH}_{4}^{+}$para

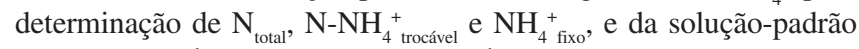
de $100 \mathrm{mg} \mathrm{L}^{-1} \mathrm{~N}^{-\mathrm{NO}_{3}}{ }^{-}+100 \mathrm{mg} \mathrm{L}^{-1} \mathrm{NO}_{2}^{-}$para determinação de $\mathrm{N}-\left(\mathrm{NO}_{3}^{-}+\mathrm{NO}_{2}^{-}\right)$. Em seguida, as soluções foram submetidas aos procedimentos descritos para as amostras. Todas as medidas de absorvância foram diminuídas daquelas dos brancos.

\section{Determinação de nitrogênio orgânico}

A concentração de nitrogênio orgânico foi calculada através da diferença entre $\mathrm{N}_{\text {total }}$ e de $\mathrm{N}_{\text {trocável total }}+\mathrm{N}_{-} \mathrm{NH}_{4}^{+}$fixo ${ }^{6,7}$. 


\section{RESULTADOS E DISCUSSÃO}

\section{Estudo do efeito da adição do catalisador de Se à mistura digestora}

Foram realizados experimentos em nosso laboratório ${ }^{33}$ para estudo do efeito da adição do catalisador de Se na etapa de digestão das amostras de rocha-reservatório e de referência certificadas, para determinação de nitrogênio total. Foi observado que não houve necessidade da adição desse elemento tóxico.

\section{Estudo da estabilidade do nitroprussiato-fenol e do indofenol}

As estabilidades do reagente nitroprussiato-fenol e do composto indofenol foram avaliadas através da comparação das cinco primeiras medidas de absorvância com as cinco últimas, aplicando-se o teste t de Student a um nível de confiança de 95\%. Observou-se que o reagente nitroprussiato-fenol permaneceu estável até pelo menos 29 dias, enquanto que as soluções contendo indofenol $\left(0,1\right.$ e $\left.0,3 \mathrm{mg} \mathrm{L}^{-1}\right)$ permaneceram estáveis até 8 dias, com exceção da solução mais concentrada $\left(0,5 \mathrm{mg} \mathrm{L}^{-1}\right)$, que se manteve estável por apenas $48 \mathrm{~h}$.

\section{Otimização do método de extração das formas inorgânicas trocáveis de nitrogênio}

\section{Efeito do tempo na extração de amônio trocável}

A Tabela 1 apresenta o efeito do tempo na extração da forma $\mathrm{N}^{-\mathrm{NH}_{4}+}$ trocável , utilizando a solução de $\mathrm{KCl} 0,2 \mathrm{~mol} \mathrm{~L}^{-1}$. Foram observadas baixas concentrações de $\mathrm{N}_{-} \mathrm{NH}_{4}^{+}$troćvel quando a separação das fases sólida/líquida foi realizada imediatamente após a mistura do extrator com a amostra $(\mathrm{t}=$ zero $)$. A maior concentração de $\mathrm{N}-\mathrm{NH}_{4}^{+}$troćvel para a amostra certificada de solo foi obtida com o tempo de extração de $30 \mathrm{~min}$. Em se tratando da amostra de arenito (amostra 9), não se observou diferença significativa, para um nível de confiança de $95 \%$, das concentrações de $\mathrm{N}_{-} \mathrm{NH}_{4}^{+}$trocável nos tempos de 30 min e $1 \mathrm{~h}$. Portanto, o tempo recomendado para extração de nitrogênio trocável foi de $30 \mathrm{~min}$.

Tabela 1. Efeito do tempo de extração na concentração de N$\mathrm{NH}_{4}^{+}$trocável utilizando o extrator $\mathrm{KCl} 0,2 \mathrm{~mol} \mathrm{~L}^{-1}$

\begin{tabular}{lccc}
\hline & \multicolumn{3}{c}{ Concentração de $\mathrm{N} \mathrm{NH}_{4}{ }^{+}$trocável $\left(\mu \mathrm{g} \mathrm{g}^{-1}\right)$} \\
\cline { 2 - 4 } & \multicolumn{3}{c}{ Tempo } \\
\cline { 2 - 4 } & Zero & 30 min & $1 \mathrm{~h}$ \\
\hline 73319 & n.d. & $43 \pm 15(\mathrm{n}=3)$ & n.d. \\
73321 & $1,5 \pm 0,1(\mathrm{n}=3)$ & $13 \pm 1(\mathrm{n}=3)$ & $6,9 \pm 0,9(\mathrm{n}=3)$ \\
73326 & n.d. & $15 \pm 1(\mathrm{n}=3)$ & n.d. \\
7 & n.d. & $24 \pm 4(\mathrm{n}=3)$ & n.d. \\
9 & $1,3 \pm 0,5(\mathrm{n}=3)$ & $11 \pm 2(\mathrm{n}=4)$ & n.d. \\
\hline
\end{tabular}

n.d. - não determinado; $\mathrm{n}$ - $\mathrm{n}^{\mathrm{o}}$ de determinações

\section{Efeito da concentração de $\mathrm{KCl}$ na extração de amônio trocável}

A Tabela 2 apresenta o efeito da concentração de $\mathrm{KCl}$ na extração da forma $\mathrm{N}-\mathrm{NH}_{4}^{+}$trocável, utilizando o tempo de extração de 30 min. Observa-se que para a maioria das amostras não houve diferença significativa entre os resultados obtidos com as duas concentrações testadas, exceto para as amostras 73326 e 9, que apresentaram maiores concentrações de $\mathrm{N}_{-} \mathrm{NH}_{4}^{+}{ }_{\text {trocável }}$ nos extratos em $\mathrm{KCl} \mathrm{0,4} \mathrm{mol} \mathrm{L}^{-1}$, sendo esse, portanto, o extrator selecionado.
Tabela 2. Efeito da concentração do extrator $\mathrm{KCl}$ na concentração de $\mathrm{N}^{-\mathrm{NH}_{4}^{+}}{ }_{\text {trocável }}$ (tempo de extração $=30 \mathrm{~min}$ )

\begin{tabular}{ccc}
\hline Amostra & \multicolumn{2}{c}{ Concentração deN-NH ${ }_{4}^{+}{ }_{\text {trocável }}\left(\mu \mathrm{g} \mathrm{g}^{-1}\right)$} \\
\hline Concentração de $\mathrm{KCl}$ & $0,2 \mathrm{~mol} \mathrm{~L}^{-1}$ & $0,4 \mathrm{~mol} \mathrm{~L}^{-1}$ \\
\hline 73319 & $43 \pm 15(\mathrm{n}=3)$ & $53 \pm 3(\mathrm{n}=3)$ \\
73321 & $13 \pm 1(\mathrm{n}=3)$ & $17 \pm 2(\mathrm{n}=3)$ \\
73326 & $15 \pm 1(\mathrm{n}=3)$ & $18 \pm 1(\mathrm{n}=3)$ \\
7 & $24 \pm 4(\mathrm{n}=3)$ & $30 \pm 2(\mathrm{n}=4)$ \\
9 & $11 \pm 2(\mathrm{n}=4)$ & $15 \pm 1(\mathrm{n}=3)$ \\
\hline
\end{tabular}

$\mathrm{n}-\mathrm{n}^{\mathrm{o}}$ de determinações

Efeito do tipo de cátion do extrator na determinação de amônio trocável

A Tabela 3 apresenta o efeito do tipo do cátion na extração da

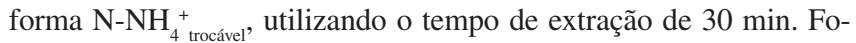
ram observadas maiores concentrações de $\mathrm{N}_{-} \mathrm{NH}_{4}{ }^{+}$com os extratos em $\mathrm{NaCl}$ 0,4 mol L -1 $^{-1}$ maioria das amostras (com exceção da amostra de referência certificada de solo 73321), indicando a presença de $\mathrm{N}_{-} \mathrm{NH}_{4}^{+}$fixo. De acordo com Stevenson ${ }^{25}$, o íon sódio expande o espaçamento $\mathrm{d}$ (001) dos minerais silicatos, permitindo aos íons $\mathrm{NH}_{4}^{+}$fixo escaparem, enquanto que o íon potássio contrai o espaçamento d (001), prevenindo a saída das formas fixas.

Tabela 3. Efeito do tipo de cátion do extrator na concentração de

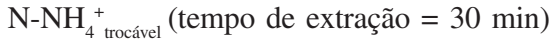

\begin{tabular}{|c|c|c|}
\hline \multirow{3}{*}{ Amostra } & \multicolumn{2}{|c|}{ Concentração de $\mathrm{N}-\mathrm{NH}_{4}^{+}{ }_{\text {trocável }}\left(\mu \mathrm{g} \mathrm{g}^{-1}\right)$} \\
\hline & \multicolumn{2}{|c|}{ Extrator } \\
\hline & $\mathrm{NaCl} 0,4 \mathrm{~mol} \mathrm{~L}^{-1}$ & $\mathrm{KCl} 0,4 \mathrm{~mol} \mathrm{~L}^{-1}$ \\
\hline 73319 & $70 \pm 5(n=3)$ & $53 \pm 3(n=3)$ \\
\hline 73321 & $12 \pm 2(n=3)$ & $17 \pm 2(n=3)$ \\
\hline 73326 & $24 \pm 3(n=3)$ & $18 \pm 1(n=3)$ \\
\hline 7 & $38 \pm 2(n=3)$ & $30 \pm 2(n=4)$ \\
\hline 9 & $23 \pm 3(n=3)$ & $15 \pm 1(n=3)$ \\
\hline
\end{tabular}

$\mathrm{n}-\mathrm{n}^{\mathrm{o}}$ de determinações

\section{Características analíticas do método de destilação com arraste de vapor/indofenol}

As características analíticas do método de destilação por arraste com vapor/indofenol foram determinadas submetendo-se massas definidas de $\mathrm{NH}_{4} \mathrm{Cl}$ às etapas de digestão, destilação e desenvolvimento de cor (Tabela 4). Os altos valores de desvio-padrão relativo (>10\%) e de branco (absorvância média de 0,112 \pm 0,008), obtidos nos primeiros experimentos, nos levaram a propor a utilização de um banho termostatizado contendo água Milli-Q, com a finalidade de estabilizar a temperatura do condensador do destilador, garantindo a condensação total da amônia, e fornecer água para caldeira, isenta de contaminação, para diminuição do branco. Sendo assim, os valores do branco e do limite de detecção (LOD) diminuíram em cerca de $73 \%(0,030 \pm 0,006)$ e $65 \%\left(9 \mathrm{mg} \mathrm{kg}^{-1}\right)$, respectivamente. Também, houve melhoria do desvio-padrão relativo para valores $\leq 8 \%, \mathrm{n}=3$. O valor do LOD obtido em nosso laboratório ( $27 \mathrm{mg} \mathrm{kg}^{-1}$ ), sem a utilização do banho termostatizado, foi concordante com o valor relatado na literatura $\left(25 \mathrm{mg} \mathrm{kg}^{-1}\right)^{8}$. O limite de detecção foi calculado pela equação LOD $=3 \times \mathrm{S}_{\mathrm{b}} / b$, onde $\mathrm{S}_{\mathrm{b}}$ é o desvio-padrão de 10 medidas do branco e $b$ é a sensibilidade da curva analítica. Foi verificada obediência à lei de Beer $\left(\mathrm{R}^{2}=0,9974 \pm 0,0009\right)$ na faixa de concentração testada $(0,05$ a 
$\left.0,5 \mathrm{mg} \mathrm{L}^{-1} \mathrm{~N}^{-} \mathrm{NH}_{4}^{+}\right)$. A absortividade molar de $(2,3 \pm 0,2) \times 10^{4} \mathrm{~L}$ $\mathrm{mol}^{-1} \mathrm{~cm}^{-1}$ é comparável àquela relatada na literatura (cerca de $2 \mathrm{x}$ $\left.10^{4} \mathrm{~L} \mathrm{~mol}^{-1} \mathrm{~cm}^{-1}\right)^{16}$.

Tabela 4. Características analíticas do método de destilação com arraste de vapor/indofenol

\begin{tabular}{|c|c|}
\hline Absortividade molar $\left(\mathrm{L} \mathrm{mol}^{-1} \mathrm{~cm}^{-1}\right)(\mathrm{n}=4)$ & $(2,3 \pm 0,2) \times 10^{4}$ \\
\hline Coeficiente de correlação $\left(\mathrm{R}^{2}\right)(\mathrm{n}=3)$ & $0,9974 \pm 0,0009$ \\
\hline $\begin{array}{l}\text { Limite de detecção }\left(\mathrm{mg} \mathrm{kg}^{-1} \mathrm{~N}^{-\mathrm{NH}_{4}^{+}}\right) \text {sem } \\
\text { banho termostatizado }\end{array}$ & 27 \\
\hline $\begin{array}{l}\text { Limite de detecção }\left(\mathrm{mg} \mathrm{kg}^{-1} \mathrm{~N}^{-\mathrm{NH}_{4}^{+}}\right) \text {com } \\
\text { banho termostatizado }\end{array}$ & 9 \\
\hline $\begin{array}{l}\text { Faixa de concentração da curva de } \\
\text { calibração }\left(\mathrm{mg} \mathrm{L}^{-1} \mathrm{~N}-\mathrm{NH}_{4}^{+}\right)\end{array}$ & $0,05-0,5$ \\
\hline $\begin{array}{l}\text { Medida da absorvância do branco }(\mathrm{n}=10) \\
\text { sem banho termostatizado }\end{array}$ & $0,112 \pm 0,008$ \\
\hline $\begin{array}{l}\text { Medida da absorvância do branco }(\mathrm{n}=10) \\
\text { com banho termostatizado }\end{array}$ & $0,030 \pm 0,006$ \\
\hline Desvio-padrão relativo $(\%)(\mathrm{n}=3)$ & $\leq 8$ \\
\hline
\end{tabular}

$\mathrm{n}-\mathrm{n}^{\circ}$ de determinações

\section{Aplicação dos métodos}

A Figura 1 apresenta os resultados das concentrações das formas de nitrogênio, de nitrogênio total e valores certificados. As recuperações de nitrogênio total, obtidas para as amostras certificadas, variaram de 99 a 108\%, sendo consideradas satisfatórias. Para efeito de comparação, os somatórios das concentrações das formas trocáveis $\left[\mathrm{N}-\left(\mathrm{NO}_{3}^{-}+\mathrm{NO}_{2}^{-}\right)+\mathrm{NH}_{4}^{+}{ }_{\text {trocável }}\right]$ foram avaliados com os resultados das concentrações de $\mathrm{N}_{\text {trocável total }}$, considerado como $100 \%$, obtendo-se recuperações satisfatórias (94 a 120\%) para todas as amostras analisadas.

A maior parte do nitrogênio está presente na forma de $\mathrm{N}-\mathrm{NH}_{4}^{+}$ (trocável + fixo) nas amostras 7 e 9 (concentrações relativas de 63 e $56 \%$, respectivamente). Esse resultado é semelhante ao relatado na literatura ${ }^{5}$ para rochas. A segunda forma mais abundante é $\mathrm{N}_{\text {orgânico }}$ (concentrações relativas de 37 e $39 \%$, respectivamente). A forma $\mathrm{N}_{\text {trocável total }}$ está presente em menor concentração (concentrações relativas de 5 e $13 \%$, respectivamente). A amostra certificada de solo 73326 também apresentou um comportamento semelhante (concentrações relativas de $\mathrm{N}_{-} \mathrm{NH}_{4}^{+}$total, $\mathrm{N}_{\text {orgânico }}$ e $\mathrm{N}_{\text {trocável total }}$ de 60,44 e $6 \%$, respectivamente). As demais amostras de referência certificadas de solo (73319 e 73321) apresentaram $\mathrm{N}_{\text {orgânico }}$ como forma predominante (concentrações relativas de 87 e $79 \%$, respectivamente), seguida da forma $\mathrm{N}_{-} \mathrm{NH}_{4}{ }_{\text {total }}$ (concentrações relativas de $12 \mathrm{e}$ $19 \%$, respectivamente) e em menor concentração, $\mathrm{N}_{\text {trocível total }}$ (concentrações relativas de 3 e $4 \%$, respectivamente).

Em todas as amostras analisadas, a maior parte do $\mathrm{N}_{\text {trocável }}$ está presente na forma de $\mathrm{N}_{-} \mathrm{NH}_{4}^{+}{ }_{\text {trocável }}$ (concentrações relativas de 65 a $100 \%)$. A forma determinada como $\mathrm{N}-\left(\mathrm{NO}_{3}^{-}+\mathrm{NO}_{2}^{-}\right)$nas amostras de rocha-reservatório, provavelmente, estaria presente nas condições originalmente anóxicas, como nitrito ${ }^{2}$.

\section{Correlação entre as formas de nitrogênio e a composição mineralógica da amostra}

As amostras 7, 9 e 73326 que contêm $\mathrm{N}^{-\mathrm{NH}_{4}+}{ }_{\text {fixo }}$ como forma predominante de nitrogênio apresentaram, na análise de difratometria de raios $\mathrm{X}^{34}$, picos indicativos da presença dos minerais muscovita/illita e feldspatos. A amostra 73326 ainda apresentou pico indicativo de clorita. As amostras 73319 e 73321, que apresentaram $\mathrm{N}_{\text {orgânico }}$ como forma predominante de nitrogênio, apresentaram picos indicativos da presença de feldspatos. De acordo com a literatura ${ }^{32,35}$, os minerais illita, muscovita, clorita e feldspatos são potencialmente fixadores de nitrogênio, sendo que a illita é um dos principais minerais responsáveis pela fixação do íon $\mathrm{N}_{-} \mathrm{NH}_{4}^{+}$. Portanto, os resultados indicam que provavelmente a forma de nitrogênio está relacionada à composição mineralógica da amostra. A Figua 2 apresenta os difratogramas das amostras 7 e 73321 .

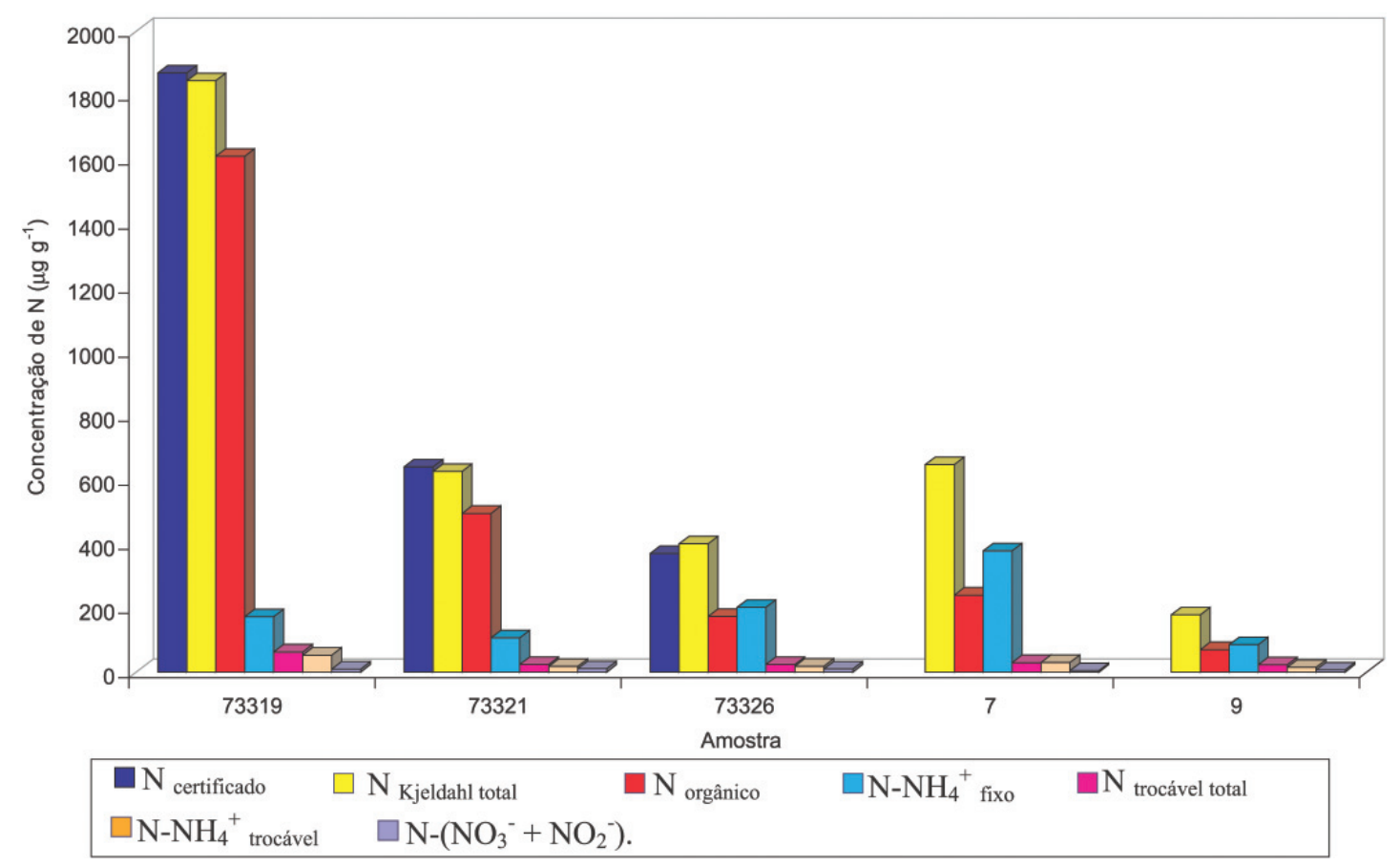

Figura 1. Concentração das formas de nitrogênio e de nitrogênio total em amostras de solo certificadas e amostras de rocha-reservatório (n=3) 


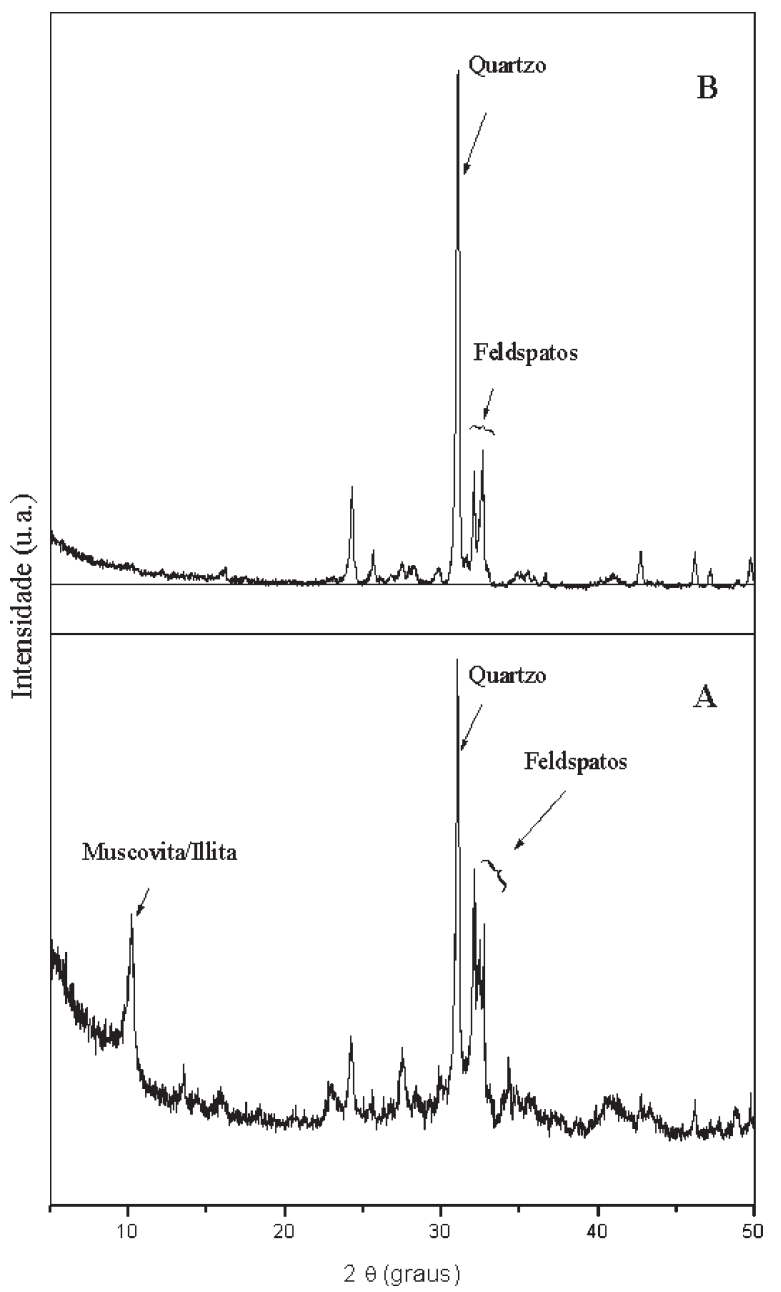

Figura 2. Difratogramas de raios $X$ das amostras de rocha-reservatório e de referência certificada de solo (A) amostra 7; (B) amostra 73321

\section{CONCLUSÕES}

A utilização de um banho termostatizado alimentado com água Milli-Q e acoplado ao sistema de destilação diminuiu os brancos em cerca de $73 \%$ e aumentou a sensibilidade em cerca de $65 \%$. O método proposto para determinação das formas de nitrogênio e nitrogênio total nas amostras de rocha-reservatório de petróleo apresentou melhores valores de LOD $\left(9 \mathrm{mg} \mathrm{kg}^{-1}\right)$ e precisão (RSD $\leq 8 \%$ ) que aqueles apresentados na literatura. $\mathrm{O}$ frasco de destilação modificado, proposto para determinação de $\mathrm{N}_{-} \mathrm{NH}_{4}^{+}{ }_{\text {trocável }}$ e $\mathrm{N}$ $\left(\mathrm{NO}_{3}^{-}+\mathrm{NO}_{2}^{-}\right)$, apresentou as seguintes vantagens: maior volume que o frasco original, permitindo a realização das destilações seqüenciais; simplicidade no manuseio do sistema de destilação; maior segurança para o analista; menor tempo de análise e eliminação de possível perda de amônia na etapa de adição da liga de Devarda. O frasco de destilação de polipropileno modificado, proposto para determinação de $\mathrm{N}_{-} \mathrm{NH}_{4}^{+}$fixo, apresentou a vantagem de simplificar a neutralização dos extratos de HF e, portanto, redução do tempo de análise. As formas de nitrogênio estão provavelmente relacionadas com as composições cristalinas das amostras de solo e de rocha-reservatório. Os métodos propostos também podem ser aplicados a solos.

\section{AGRADECIMENTOS}

Este trabalho foi desenvolvido com o financiamento e incentivo do Projeto CT-PETRO/Rocha, convênio $N^{\circ}$ 2.1.01.0700.00 firmado em parceria com a PETROBRAS/CENPES, FINEP e REQARJ. Agradecemos ao Dr. C. H. de Oliveira pelas análises de DRX.

\section{REFERÊNCIAS}

1. Holloway, J. M.; Dahlgren, R. A.; Casey, W. H.; Chem. Geol. 2001, 174, 403.

2. Madigan, M. T.; Martinko, J. M.; Parker, J.; Microbiologia de Brock. PearsPrentice Hall: São Paulo, 2004.

3. Bishop, J. L.; Banin, A.; Mancinelli, R. L.; Klovstad, M. R.; Planet. Space Sci. 2002, 50, 1.

4. Hatton, D.; Pilarski, J.; Pickering, W. F.; Chem. Speciation Bioavailability 1990, 2, 139.

5. Jeffery, P. G.; Chemical Methods of Rock Analysis, Pergamon Press, Ltd.: Oxford, 1970, p. 359-360.

6. Bremner, J. M.; Total Nitrogen. Methods of soil analysis Part 2- Chemical and Microbiological Properties number 9 in the series Agronomy, American Society of Agronomy Inc.: Publisher USA, 1965, p. 1149-1178.

7. Keeney, D. R.; Bremner, J. M.; Soil Sci. 1967, 104, 358.

8. Wang, D.; Snyder, M. C.; Bormann, F. H.; Soil Sci. Soc. Am. 1993, 57, 1533 .

9. Yasuhara, T.; Nokihara, K.; J. Agric. Food Chem. 2001, 49, 4581.

10. EMBRAPA - Empresa Brasileira de Pesquisa Agropecuária. Manual de Análises Químicas de Solos, Plantas e Fertilizantes; Comunicação para Transferência de Tecnologia, Brasília: Brasil, 1999.

11. Stevenson, F. J.; Geochim. Cosmochim. Acta 1962, 26, 797.

12. Standard Methods for Examination of Water and Wastewater; $20^{\text {th }}$ ed., American Public Health Association: Washington, 1998, p. 4-99 e 4-124.

13. FEEMA; Fundação Estadual de Engenharia e Meio Ambiente; Manual do meio ambiente; métodos; Rio de Janeiro: Brasil, 1983, p. 43.

14. van Standen, J. F.; Taljaard, R. E.; Anal. Chim. Acta 1997, 344, 281.

15. Scheiner, D.; Water Res. 1976, 10, 31.

16. Kanda, J.; Water Res. 1995, 29, 2746.

17. Verdouw, H.; van Echteld, C. J. A.; Dekkers, E. M. J.; Water Res. 1978, $12,399$.

18. Kempers, A. J.; Kok, C. J.; Anal. Chim. Acta 1989, 221, 147.

19. McLeod, S.; Anal. Chim. Acta 1992, 266, 113.

20. Patton, C. J.; Crouch, S. R.; Anal. Chem. 1977, 49, 464.

21. Bremner, J. M.; Keeney, D.R.; Soil Sci. Soc. Am. Proc. 1966, 30, 577.

22. Hatton, D.; Pilarski, J.; Pickering, W. F.; Chem. Speciation Bioavailability 1992, 4, 53.

23. Tabatabai, M. A.; Commun. Soil Sci. Plant Anal. 1974, 5, 569.

24. Blackburn, T. H.; Henriksen, K.; Limn. Oceanogr. 1983, 28, 477.

25. Stevenson, F. J.; Science 1959, 130, 221.

26. Sims, J. R.; Jackson, D.; Soil Sci. Soc. Am. Proc. 1971, 35, 603.

27. Haby, V. A.; Soil Sci. Soc. Am. J. 1989, 53, 308.

28. Vendrell, P. F.; Zupancic, J.; Commun. Soil Sci. Plant. Anal. 1990, 21, 1705.

29. Bremner, J. M.; Bundy, L. G.; Agarwal, A. S.; Anal. Lett. 1968, 1, 837.

30. Stewart, B. M.; J. Soil Sci. 1987, 38, 415.

31. Haendel, D.; Mühle, K.; Nitzsche, H.-M.; Stiehl, G.; Wand, U.; Geochim. Cosmochim. Acta 1986, 50, 749.

32. Dhariwal, A. P. S.; Stevenson, F. J.; Soil Sci. 1958, 86, 343.

33. Monteiro, M. I. C.; da Silva, L. I. D.; Carneiro, M. C.; Relatório Interno CETEM 2003-088-00, Centro de Tecnologia Mineral, Rio de Janeiro, Brasil, 2003.

34. Oliveira, C. H.; Boletim de Análises SCT 037/04 da COAM/ CETEM, Rio de Janeiro, Brasil, 2004.

35. Mingram, B.; Bräuer, K.; Geochim. Cosmochim. Acta 2001, 65, 273. 